\title{
Maritime and Other Key Transport Issues for the Future - Education and Training in the Context of Lifelong Learning
}

\author{
Jeannette Edler ${ }^{a}$, Virginia Infante ${ }^{b}$
}

The entire transport system will transform into an integrated transport system in response to future trends and demands. The EU Skilful project defines the impact on job profiles across all transport modes and at all levels of work and duties. Changing and emerging job profiles require training which on the one hand makes use of the latest training and education methods, while on the other meeting the need for the acquisition of special competencies, skills and abilities. The demand for individualization of training contents will soar in the interlinked global world and integrated transport systems.

An additional questionnaire was conducted in the spring of 2018, in the assessment of the maritime and transport sectors. The answers of course lecturers and organisers concerning

\section{KEY WORDS}

$\sim$ Lifelong learning

$\sim$ Future transport

$\sim$ Training and education

$\sim$ Emerging and new job profiles

$\sim$ Employees' needs

\author{
a. ISV e.V., Institute for Safety Technologies and Ship Safety, Rostock-Warnemünde \\ e-mail: j.edler@schiffssicherheit.de \\ b. Instituto Superior Técnico, Lisboa \\ e-mail: virginia.infante@tecnico.ulisboa.pt \\ doi: 10.7225/toms.v08.n01.009 \\ This work is licensed under (cc) BY
}

present and future needs and lifelong learning issues were instructive, with most of the people having concrete ideas about lifelong learning.

Courses will therefore include future oriented contents, a practicable registration procedure with information for qualified trainers capable of tailoring course contents to the specific focus of the course and participants' requirements, giving excellent lectures with relevant learning material and real usable factors, clear structure, practical parts, remarks of concrete relevance, communication parts for improving soft skills, experience exchange and learning from other participants, intercultural aspects for globalization, reconciling mixed group needs and requirements and learning to learn methods, using different adult suitable methods and finally focusing on emotions to capitalize on the motivation to learn.

Lifelong learning is a key issue for successful employers and employees.

\section{INTRODUCTION}

More than 11 million people in Europe are directly employed in the transport industry (EU Transport Policy, 2014; European Commission, 2014; EUROSTAT, 2011; Transport in Europe, 2016; Deliverable D1,1), accounting for $4.5 \%$ of total employment in the European Union. If transport equipment manufacturing is included, the figure can be increased by an additional $1.5 \%$ of EU employment in the direct and indirect transport sector (EU Transport Policy, 2014; European Commission, 2014; EUROSTAT, 2011; Transport in Europe, 2016; Deliverable D1,1). 
Transport is changing due to the new impacts such as globalisation, electrification, smart technologies, 3-D-printing, alternative fuels, more renewable energies, alternative propulsion systems, big data, automatization, new transport concepts like mobility as a service, transport on demand and autonomous vehicles (Deliverable D1.1). Other aspects, like demographic change, global warming or climate change, will likewise influence the transport sector.

Employability has a central role in the Europe 2020 strategy and the Education and Training 2020. Vocational education and training, academic qualifications and lifelong training have a direct impact on employability and chances of employability.

Due to the future changes in professional positions owing to the mentioned paradigm shifters and game changers like, for example green and smart transport, automatization, digitalisation and innovative transport concepts, there is a perceived lack of education and training, including in the field of lifelong learning. There are:

- Jobs/ positions which will be eliminated or vanish in the short-term, medium-term and long-term horizon (Deliverable D1.1),

- Jobs/ positions which will emerge in the short-term, medium-term and long-term horizon (Deliverable D1.1),

- Jobs/ positions which will change in the short-term, medium-term and long-term horizon (Deliverable D1.1).

The EU Skilful project, funded by the European Union's Horizon 2020 research and innovation programme, is mainly focussed on the development of skills and competences of future transportation professionals at all levels and for all modes. The "Skilful" aimed to identify future transport trends across all transport modes, establish the main impacts on present job profiles and finally to give recommendations for the future for low-, middle- and high skilled employees. This paper refers mainly to the maritime sector.

\section{FUTURE TRANSPORT ISSUES}

\subsection{Maritime Transport Trends}

Transport will change in the next decades due to growing population, urbanisation and changes in consumer needs. (Tipping, Schmal \& Duiven, 2016).

Non-industrial, underdeveloped regions and countries suffering from overpopulation and/or food shortage caused by climate change will be forced to import more food and consumer goods. Price policy and availability will be decisive for the origin of these goods. Transport will change in Europe as well, due to infrastructural limitations. There must be a movement towards more seaborne and rail-borne short-distance transport, instead of transport by trucks or other road vehicles.
India and China will be number 1 in total population. People tend to live longer, couples will grow less children and the society will become richer. China, the USA and India will be the biggest economies in 2030. Consumer purchasing power will increase until 2030, with the developing Asia growing by a factor of eight and the OECD region by a factor of three. (Argyros \& Smith, 2013) Maritime transport mode currently accounts for nearly $90 \%$ of global trade transport. (Castonguay, 2015; UNCTAD, 2017)

Climate change costs will increase, causing water shortages in southern regions like Africa or Australia, with global warming reshaping the coastal zones. (Argyros \& Smith, 2013; Saxon \& Stone, 2017)

The transport of raw materials and resources will increase due to the global population growth, climate change and the anticipated impacts of easy 3-D-printing which will influence consumer demands and shipping tonnage. Easy 3-D printing is estimated to have real global impact approx. 20-50 years from now. (AEB, 2016; Müller \& Karevska, 2016; DHL Trend Research, 2016)

\subsection{Autonomous Shipping and New Shipping Routes}

The usage of the Arctic and Atlantic trade routes will increase due to global warming and the minimization of ice, while the Suez Canal will probably lose importance. Unsafe passages will be avoided. (Argyros \& Smith, 2013; Saxon \& Stone, 2017)

Autonomous shipping will partly increase at different stages of long distance passages or short tracks. Another important factor will be the autonomous shipping of the future. Several levels of remote-controlled, partly and fully autonomous ships will be developed in the next decades and used in short and long distances shipping, all traversing the same oceanic waterways. (AAWA, 2016; MSC 98/20/2; Parasuraman, Sheridan \& Wickens, 2000; Twomey \& Berry, 2016; Blanke, Henriques \& Bang, 2017; DNV GL, 2019)

Another new application are automated mooring systems. (Cavotec, 2017)

\subsection{Alternative fuels: Decarbonisation, Electrification / Energy / Environmental Protection}

Transport by ships is currently the most energy efficient mode of transport, anticipated to become increasingly decarbonised like other transport sectors due to the finite nature and instability of fossil fuel supply and the necessary reduction of greenhouse gases. However, the efforts will depend both on the availability of marketable alternative fuels which will replace today's heavy fuel oil and on the already starting era of LNG or LPG, methane or electrification by fuel cells, already approved by the IMO. There will be a need for the establishment of 
supply infrastructure for the comprehensive, nationwide use of alternative fuels.

China will become the largest oil consumer in 2030, and the US the biggest natural gas consumer. Natural gas consumption in the Middle East and Europe will overtake oil consumption in 2030. China and India will have the biggest steel consumption in the world, causing iron ore to remain an important seaborne cargo in 2030. (Argyros \& Smith, 2013)

New technologies will support green, smart and clean power supply in the port shore connections, as well as the reduction of energy consumption, and effective control and management of available energy. (Grolinger et al. 2016; Acciaro \& Wilmsemeier, 2015)

Another important factor is the increasing awareness of the protection of the maritime inventory and the sensitive marine ecosystems. The number of initiatives to develop technologies which reduce the negative impacts of humans on the ocean, e.g. reduce underwater noise and optimize shipping efficiently, will grow. (Hagen, 2017)

Moreover, the ocean, as the home of blue biotechnology and resources, will come into greater focus as means to meet the increasing demand for food and medicines, as well as a potential source of renewable energy, like optimized offshore wind turbines, ocean tidal power stations or ocean current power plants. The ocean will consequently come under even bigger pressure as a space for different existing and new uses and demands.

\subsection{Digitalisation "Maritime 4.0"}

The maritime industry is one of the most important economic sectors of the future and has to come to terms with more than one megatrend like the fourth industrial revolution, the digitalisation.

Ports will become increasingly interconnected and digitized. Appropriate infrastructure is of great importance, with the use of the data obtained emerging as a new field of interest in reaping valuable efficiency, security and energy saving benefits. (Hagen, 2017; Jahn, 2017)

On the other hand, data management, evaluation, safety and flow are new problem areas. The opportunities of digitalization are the development of new processes, production, ship operations, port and cross-modal aspects, as well as the overall port logistics. Innovative port technologies will become key competitive advantages. Process modifications are anticipated to increase efficiency. The collection and consolidation of data, combined with intelligent forecasting models for weather, navigation, ship operation and specific (cargo) vessel data, interconnected with hinterland traffic systems and logistics centres, will develop into an optimized logistics chain with efficient ship and port operations. If production is also connected, digital lifecycle management could no longer be merely a concept of an entire logistics chain. The safety of all networked systems is one of the most important factors for the future. (Shaikh, 2017; Hiranandani, 2014)

\subsection{Shipbuilding}

Sustainable, smart, green shipbuilding will become the main task and a new business field in the yard industry of the future, with integrated complex systems to meet the expectations of the next decades. Climate friendly and environmental friendly products will have big potential. Shipbuilding industry has to adjust to the future trends in shipping, e.g. by building more passenger ships to meet the needs of growing population and due to the negative balances of freight transport, taking advantage of opportunities like 3-D-printing or the naval industry, due to the increasing risks of terrorism or private interests. There will be big differences between Europe, Asia and America. There will be more competition between Asia and Europe. IT-based development in ship design and shipbuilding will result in increased innovation dynamics, faster implementation and customization, small series at competitive costs. $3 \mathrm{D}$ printing will also come to be used in production. Material, component and system providers are very important actors due to the fact that $70-80 \%$ of added value in ship construction is created by the supplier business makes shipyards future system integrators.

\subsection{Marine Technology / Deep Sea Mining / Offshore and Floating Platforms}

The development of offshore oil and gas exploration and exploitation technology will go hand in hand with the opening up of new mining technically challenging fields like deep-sea mining for gas hydrates and renewable energies like ocean currents. Blue biotechnology and deep sea mining require the use of deep-sea robots, unmanned remote-operated vehicles, state-of-the-art digital observation technology, production of powerful offshore oil and gas conveyors. Floating platforms will also be an option for innovative systems- likewise meeting the needs of new zones for population.

\subsection{Retrofitting /Maintenance}

Services will become one of the most sought-after working fields of the future. The need of qualified retrofitting and repair workforce for ship and port operations, shipyards, supply business, machinery and equipment manufacturers, will grow owing to the increasing number of ships, plants and uses in the ocean. 
The use of constantly evolving digital technologies is important. The effective realization of potential for innovations, further development of new technologies, strengthening crossinnovations for cross-sectoral development of technologies and activities, interdisciplinarity and the growing innovative power are required. Worldwide harmonization of international standards will be the main success factor in the maritime industry. For Europe to be competitive, it must harmonize interfaces and data formats. Strategic partnerships seem to be one of the most promising components.

\subsection{Education and Training}

Over 1.2 million people are directly employed in the shipping industry as both seafarers and port workers. If logistics, supply chain management and other shipping related businesses are included, the figure increases to tens of millions worldwide. (Castonguay, 2015)

The increasing trend of utilization of complex systems in maritime-related businesses and the use of new, smart information and communication technologies and digitalisation in shipping, port logistics, offshore and maritime technologies will transform the skills required of maritime professionals to include more extensive or specialised contents and abilities. (Hagen, 2017; DNV GL Shipping, 2019)

Ongoing digitalization requires the development of a trustful dialogue between educational and training institutions, in addition to the promotion of education and training. The development of qualified personnel will be the main task of the future. Investment in not only hardware and software, but also in human resources will secure and create many maritime jobs, although their profile will dramatically change.

\subsection{Endangered Jobs, Changing Job Profiles and New Job Profiles}

The trends and the set of consequently required skills and competencies suggest that the following job profiles will be eliminated in short (2020-2030), middle (2030-2045) or long term horizon (from 2045/2050) (Bekiaris \& Loukea, 2017; Ahern et al., 2019). Over the next couple of decades, mainly manual jobs are anticipated to become obsolete and replaced by technical and automated jobs using electrification and new technologies like automation and robotics. Recurring workflows and repetitive

Table 1.

Endangered Job Profiles.

[own summary in accordance with Bekiaris \& Loukea, 2017; Ahern et al., 2019].

Endangered maritime transport job profiles in the short term

Manual port operators (e.g. stevedores, machine operators, conductors, loaders/ unloaders, mooring personnel)

\begin{tabular}{lll}
\hline Manual warehouse operatives & $\begin{array}{l}\text { Traditional fuel station operators and fuel } \\
\text { station maintenance personnel }\end{array}$ & Port managers \\
\hline Ticket issuers and ticket controllers & Port operatives & Decentralised maritime traffic managers \\
\hline Freight forwarders & Package handlers & Office-based dispatchers \\
\hline Logistic centre staff & Toll collectors and toll handling clerks & $\begin{array}{l}\text { Preventive maintenance technicians and } \\
\text { engineers }\end{array}$ \\
\hline Clerks handling transport documents & Booking clerks, Travel agents & Technicians for port vehicles \\
\hline Onsite/Outdoor maintenance staff & Maritime traffic violation officers & Signallers \\
\hline Inspectors/ Quality inspectors & Security guards & Insurance agents \\
\hline Schedulers & Fossil fuel transport deliverers & \\
\hline $\begin{array}{l}\text { Manufacturing personnel (blue collar } \\
\text { worker) }\end{array}$ & Ship crew & \\
\hline & Steel production manufacturers & \\
\hline & $\begin{array}{l}\text { Controllers and low level data } \\
\text { interpretation clerks }\end{array}$ & \\
\hline HR Administration personnel \\
\hline
\end{tabular}

Endangered maritime transport job profiles in the long term

Dispatchers profiles in the medium term

Drivers (truck driver, logistics drivers, drivers in ports)
Endangered maritime transport job 
Table 2.

Changing and New Job Profiles.

[own summary in accordance with Bekiaris \& Loukea, 2017; Ahern et al., 2019].

\section{Changing Maritime Transport Jobs}

Drivers

Manual Operators

Ticket issuers \& controllers

Freight forwarders, Logistic centre staff

Booking clerks \& travel agents

Transportation schedulers/planners

Mobility planners

Customer service personnel

Customer suppliers \& suppliers planning, Custom officials

Manufacturing staff

Fuel station operators, fuel distributors and retailers, fuel quality control personnel

Maritime traffic police

Security controllers

IT engineers

Security managers

Driving license instructors
New maritime Transport Job Profiles

Logistics managers

Global freight forwarders/managers

Logistic operators at terminals \& delivery dispatchers/

City logistics service providers

Experts on Al, Digital transformation, Big data

loT developers, loE Engineers, 3D Printing Engineers

Automation \& Robotics experts

Innovators development \& maintenance of automated systems

Predicting engineers

Alternative fuels distributors \& Alternative fuel station operators

Charging station operators \& managers

E-charge maintenance technicians

Remote flying object operators

Automated vehicle operators

Drones operators

Designers of autonomous vehicles, ships

Security \& cyber security experts

Legal services personnel and privacy protection specialists

Info-mobility experts

Ethics and law specialists in transportation

Mobility integrators \& MaaS aggregators/ Integrated transport

system planners

Smart delivery: Transport planners \& tool developers operating cycles in a static environment will be replaced by robots and automated machinery. Digitalization will accelerate workflows, rendering low-skilled, straightforward, simple bureaucratic jobs, paperwork and simple tasks redundant. Jobs involving the application of simple rules and simple decision making will also be replaced by computerized automatism and technologies. The blue collar worker executing manual tasks will become increasingly unnecessary, owing to the new maintenance philosophy and servicing modes preferring the replacement of entire units, like in the airplane industry, and well-organised maintenance in specialized workshops instead on-site. Experts will program machinery and computers to learn about maintenance and failures, after which the machines will learn by themselves (artificial intelligence). Autonomous driving will replace real drivers and intelligent networks, steered by intelligent predicting computer programmes using multiple sensors enabling them to take all traffic participants into account will take over the operation of autonomous vehicles and ships. Security duties will be replaced by watch-keeping drones, sensors and decision-making intelligent data programmes. (Bekiaris \& Loukea, 2017; Ahern et al., 2019)
There will be a transition period in which jobs will completely or partly vanish or change. This interim period will be very important for innovators, employees and employers since accumulated existing and available knowledge needs to be saved and carefully transferred into new technologies. This circumstance will be decisive for the speed of implementation of new technologies, the pace of process adoption and sustainability. Employees have to be motivated, openminded, convinced and even fearless. Employers have to take the employees along and give them the opportunity to influence the processes, change their minds in their own time and decide to lend valuable support to the altered processes. Nevertheless, all groups participate in system alteration, have to find their new roles and fulfil their tasks.

Alteration implementation should be a bit easier in the case of changing job profiles, since there should be a basis to work on and a starting point for the adoption of new topics, instruments, processes and technologies. The traditional manual work processes will be replaced by workflows using robots and machinery. Employees are familiar with the traditional workflow, the starting point, the materials used, the support systems and 
statistics in the European Union (EU) are based on data collected through the labour force survey (LFS) and the adult education survey (AES). The Adult Education Survey (AES) is one of the main data sources for EU lifelong learning statistics. In this context adult learning means the participation of adults aged 25-64 in lifelong learning. Four forms of further educational activities were formulated:

- courses or courses at work or leisure,

- $\quad$ short-term educational or training events, like lectures, trainings, seminars or workshops,

- $\quad$ on-the-job training (e.g. scheduled instructions or training by supervisors, colleagues, through trainers or teletutors),

- $\quad$ private lessons during leisure time (e.g. driving lessons for driving license, coaching lessons in sports, music lessons, tutoring lessons).

In the AES, lifelong learning, limited to the 18-64 year old group, is the starting point for capturing various learning. On the conceptual basis, the CLA (Eurostat 2016) includes three types of learning: Formal Education (FED, means regular or formal learning), Non-Formal Education (NFE, contains continuing education) and Informal Learning (INF). These three different types of learning vary depending on the degree of their organisation. (Bilger, Behringer \& Kuper, 2013)

\subsection{Labour Force Survey (LFS)}

The reference period for participation in (formal and nonformal) education and training are the four weeks immediately preceding the interview, as is usual in the LFS. In 2016 in the EU-28, the share of persons aged 25 - 64 who participated in education or training was $10.8 \%$; which is $1.7 \%$ more than in 2011. Denmark, Sweden and Finland had much higher shares of adults' participation in lifelong learning in the four weeks preceding the interview. The Netherlands, Estonia, Luxembourg and France were the only other member states of the European Union to reach the $15 \%$ benchmark. In Austria and the United Kingdom the participation rate in 2016 came close to the $15 \%$ benchmark with 14,9 and $14,4 \%$ respectively. Romania, Bulgaria, Slovakia, Croatia, Poland and Greece have the lowest rates of adult participation in lifelong learning with $4.0 \%$ or less. In the EU-28, women's participation rate of $11.7 \%$ in 2016 was higher than the men's 9,8\%. However, it should be pointed out that the shares for both were higher in 2016 than in 2011. (Vemuri, 1993)

\subsection{Adult Education Survey (AES)}

Information about education and training is also available from the AES. The data shall be interpreted in addition to the LFS which contains information about participation in education and training in the four weeks before the survey interview. The difference between the methods used by the AES and the LFS is the reference period, i.e. the LFS is concerned with participation in education and training during the 12 months preceding the survey interview. Furthermore, the AES is carried out only every 5 years. According to the AES 2011, $40.3 \%$ of persons in the EU-27 aged 25-64 took part in education and training (during the 12 months preceding the interview), the majority of which was nonformal. Participation rates in education and training in the EU27 were almost the same for men and women. While in Finland, Latvia and Lithuania women participated in education and training more frequently, men had higher representation shares in the Netherlands and Germany. In 2011 the participation rates of younger persons (aged 25-34) in the EU-28 were nearly twice as high as those of older employees (aged 55-64). (AES, 2011)

The three most cited among the eleven obstacles to participation in education and training are:

- no need for training (50.0\% in the EU-27)

- lack of time due to family responsibilities (20.9\%)

- $\quad$ and conflict with work schedules (18.0\%). (AES, 2011)

Judging from the legal framework and the ambitious benchmarks, access of European employees to lifelong learning varies significantly and there is a considerable difference between northern and southern countries, as well as in their economies. Employees who live in the north have a better chance of taking up future trends, improving their employability and taking next career steps, and employers in the north invest not only in modern technologies, but in human resources as well.

\subsection{Lifelong Learning Strategies}

"You can't teach an old dog new tricks- can you?"

Lifelong learning and training means all learning activities undertaken throughout life to develop competencies and qualifications, with the aim of improving knowledge, skills and/ or qualifications for personal, social and/or professional reasons.

\subsubsection{Advantages and Obstacles for the Society, Employers and Employees}

Lifelong learning and training are advantageous for societies, employers and employees. The advantages of lifelong learning are manifold: societies benefit from employees who share new technologies, from new impulses and other branches. Lifelong learning increases mobility, internationality and employability. Less time is lost due to sicknesses, insurance and social system costs decrease. Incentives for employers, like grants or tax benefits, could be provided by the state. Certificates, keeping the human resources and preserving accumulated knowledge. Motivation increases and fluctuation decreases, improving the independence of companies. Other advantages for the employer are increased critical thinking, problem solving, preparedness and willingness to work. As for the employees, the 
advantages of active participation in lifelong learning are high qualification, ability, eligibility. Added values for the employees could be incentives like paid leave for education, more vacation or even higher wages.

On the other hand, lifelong learning and training have to overcome the same obstacles as societies, employers and employees.

It is not an overstatement to say that the availability, quality and quantity of a society's technical infrastructure could be obstacles, as could the acceptance of appreciation of lifelong learning, social motivation and financial support by the administration and existing conditions like employment and qualification. With respect to employers, the four greatest obstacles are the loss of working hours, personal gaps, costs and organizing efforts. Furthermore, there is fear of overqualification of personnel, interlinked with the fear for turnover and fluctuation, and last but not least, fear of leadership problems in case of smart employees. Obstacles encountered by employees are money, effort, time, fear of asking the boss, bureaucracy, demotivation, lethargy. Some employees also have fear of the new or fear of failure, and problems with the acceptance of personal and professional setting and environment.

\subsubsection{Half Life of Knowledge}

An individual's available knowledge changes throughout his/her life. That's another reason why everyone needs lifelong training. Current expertise and knowledge become irrelevant, incorrect or lost over time. While half of the knowledge obtained in school is lost after 20 years, 50 percent of knowledge gained at the university is forgotten in 10 years. The value of professional expertise plummets by 50 percent after 5 , technical knowledge after 3 and IT expertise after $1-2$ years. As for content relevance, knowledge from the field of mechanical engineering can be said to become incorrect or obsolete after 20, medical knowledge after 10, traditional marketing after 7 years and social media marketing after 1 year or less. (Vemuri, 1993)

\subsubsection{Social Lifelong Learning Framework}

The framework of lifelong training includes aspects like legal requirements, the mandatory nature of the course or lack thereof, the time aspect, costs and duration, as well as the existence of standards for courses, their content and objectives, or lack thereof.

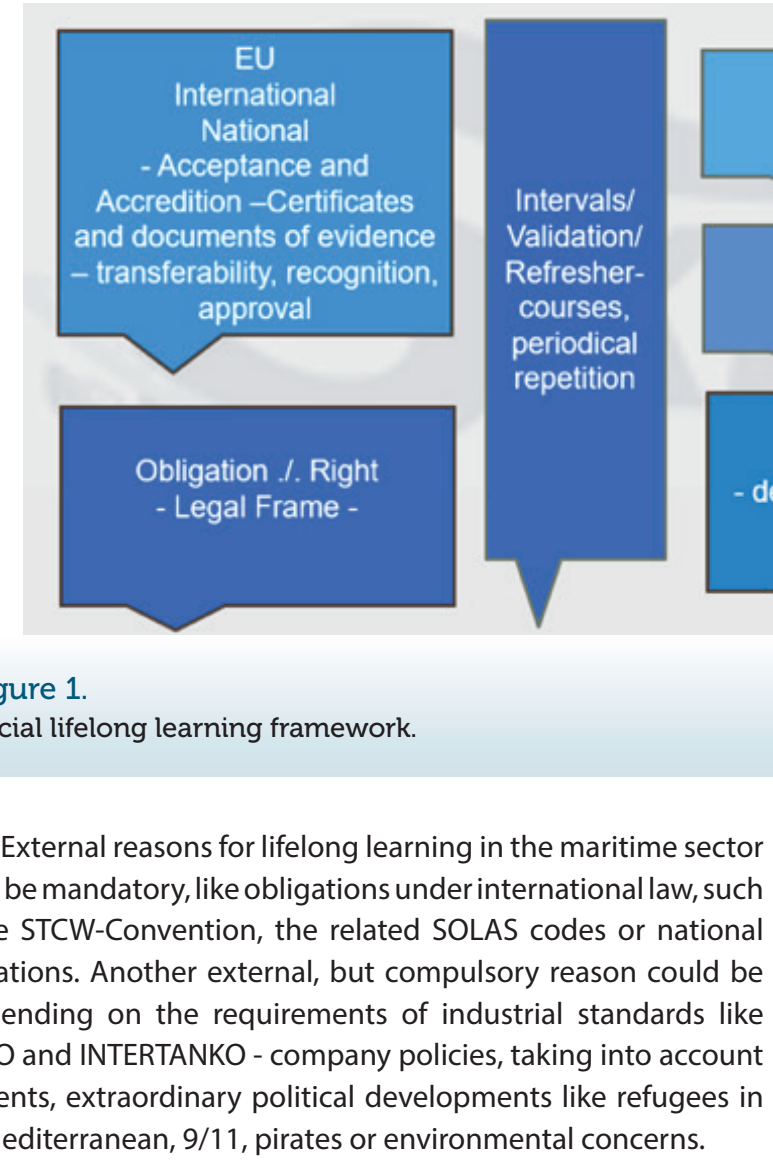

\subsubsection{General Lifelong Learning and Training Content}

In the following scheme all content-related aspects of lifelong learning are visualised. There are competences and skills falling under the heading health ( 3 types of grey) in which individuals should be trained and educated, although the team (dark grey) is also an important aspect which should be involved in lifelong training. The lifelong training process is characterised 


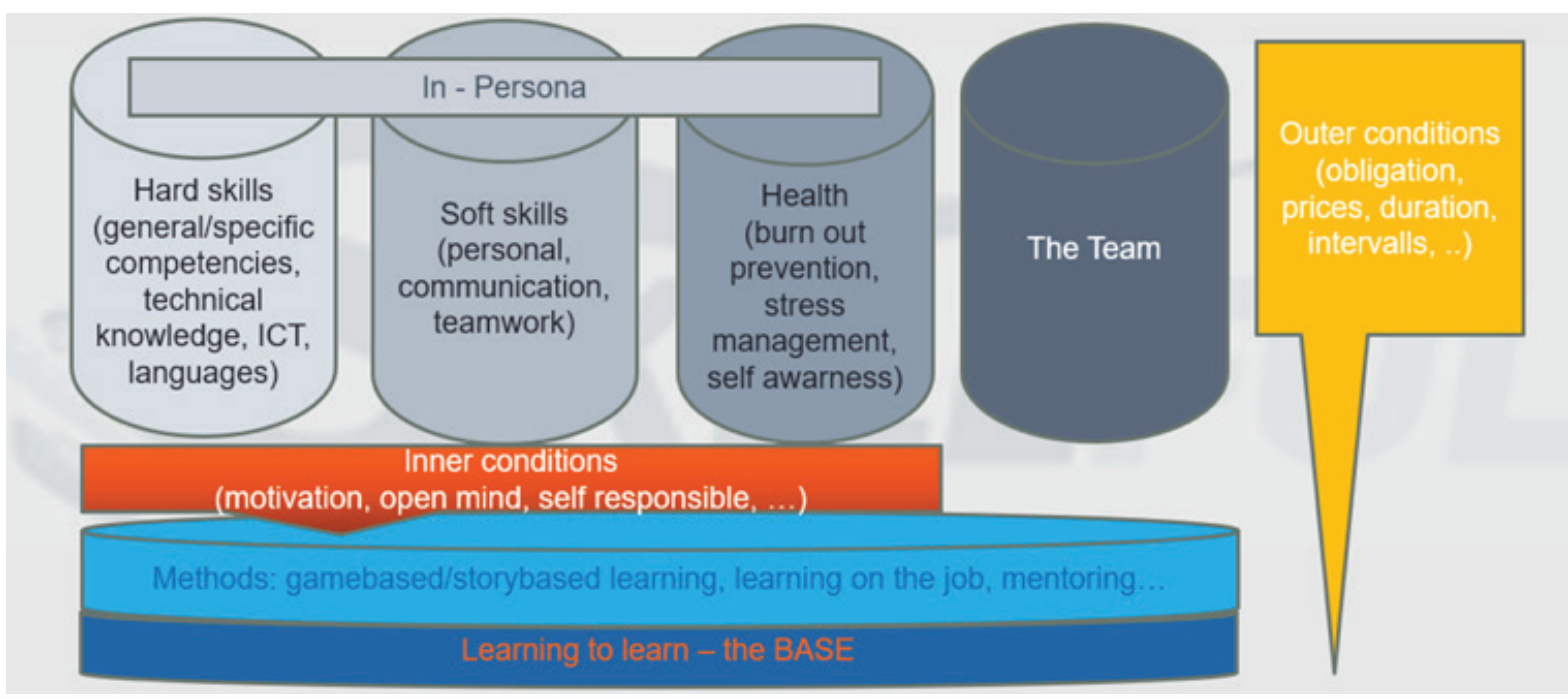

Figure 2.

Lifelong learning and training content columns scheme.

Table 3.

Time-related training schemes..

\begin{tabular}{|c|c|c|c|}
\hline Category & Minimum & Intermediate & Maximum \\
\hline \multicolumn{4}{|l|}{$\begin{array}{l}\text { According to legal } \\
\text { Requirements }\end{array}$} \\
\hline Interval & $\begin{array}{l}\text { STCW refresher all } 5 \text { years + new courses or } \\
\text { training by the job (familarization) }\end{array}$ & All 2-3 years & Monthly, every half year \\
\hline Content & $\begin{array}{l}\text { Education and Training only according to the } \\
\text { law (mostly knowledge-oriented), general }\end{array}$ & $\begin{array}{l}\text { Minimun Variant + } \\
\text { knowledge, skills, team, } \\
\text { general and object } \\
\text { related individual }\end{array}$ & $\begin{array}{l}\text { Intermediate Variant + } \\
\text { individual needs oriented }\end{array}$ \\
\hline Duration & According to the law & & $\begin{array}{l}1 / 2 \text { day-a few days, depending } \\
\text { on object }\end{array}$ \\
\hline Orientation & According to the law, general & Needs of company & $\begin{array}{l}\text { Needs of trainee and company, } \\
\text { individual }\end{array}$ \\
\hline $\begin{array}{l}\text { Sustainability / } \\
\text { Preservation of } \\
\text { knowledge, skills }\end{array}$ & $\begin{array}{l}\text { According to the law suficient, but less } \\
\text { effective, not suitable e. g. for ICT }\end{array}$ & ICT conform & $\begin{array}{l}\text { Best variant, enough time for } \\
\text { refreshment of various contents }\end{array}$ \\
\hline $\begin{array}{l}\text { Growth of } \\
\text { knowledge, skills }\end{array}$ & $\begin{array}{l}\text { Only according to the law, topics identified } \\
\text { by authorities, administration, less growth } \\
\text { because of less time / periods }\end{array}$ & $\begin{array}{l}\text { Corresponding to } \\
\text { interval and objects, } \\
\text { better than minimum }\end{array}$ & Excellent possibilities \\
\hline Actuality & $\begin{array}{l}\text { Sufficient, but sometimes delayed because of } \\
\text { slow law enforcement }\end{array}$ & More actual & $\begin{array}{l}\text { Up to date, also including } \\
\text { newest technologies }\end{array}$ \\
\hline Costs & $\begin{array}{l}\text { According to the law, at first sight minimum } \\
\text { effort but... }\end{array}$ & $\begin{array}{l}\text { More expensive than } \\
\text { minimum variant on first } \\
\text { sight, but... }\end{array}$ & $\begin{array}{l}\text { More expensive variant, but } \\
\text { only on first sight... }\end{array}$ \\
\hline
\end{tabular}


by inner (orange) and outer conditions (yellow). Various methods used in lifelong training are suitable for the education and

There are three time-related lifelong learning schemes. The minimum version, barely meeting the legal requirements with a long term horizon and the intermediate alternative with midterm brushing up of knowledge and soft skills, as well as further qualification, depending on the work and the position, are not preferable. The maximum short-term version includes continuous, e.g. half a day per month, 1 day every 3 or 6 months, mixed and need-oriented content, involving the repetition of basics and the acquisition of new know-how, improvement of soft skills, health awareness and team aspects. It provides sufficient time to take a look at the shortcomings and needs of the team and the company, further qualification and development of individual employees, the team and the company. The performance, work force, quality of the work, employee satisfaction and know-how of the employees and the company improve when the periods between lifelong training courses decrease. Table 3 shows the differences between several time-related schemes in terms of several aspects, like legal requirements, content, duration, orientation, sustainability, growth of knowledge and skills, actuality and costs.

The maximum, short-term variant is the most preferable.

\section{ASSESSMENT OF LIFELONG TRAINING SCHEMES IN THE TRANSPORT SECTOR}

In the light of future trends and bearing obstacles in mind, the partners of the Skilful project devised novel training schemes for low to medium skilled transport professionals, with the aim of meeting the requirements of future transport systems and the needs of adult transport professionals by providing lifelong training schemes enhancing quality and transparency, and promoting the recognition of competencies and qualifications to increase the mobility of learners and employees. (Ahern et al., 2019) The use of ICT/C-ICT on-board technologies, cyber security, technical inspection and maintenance of clean ships and infrastructures by the relevant technical staff, environmental issues like alternative fuels and alternative propulsion, new shipping routes and new approaches for infrastructure managers and intermodal terminal and logistics experts, are some of the content-related aspects of lifelong training schemes. (Ahern et al., 2019)

A questionnaire with 27 different question types (open or closed, yes, no, no answer, alternative 1, 2, etc.) was designed to be answered by institutions which organize lifelong learning courses in the framework of the Skilful project, inquiring about used or planned methods, communication tools and motivating parts and aiming to get further detailed information on the characteristics of lifelong learning courses and the awareness of the institutions proposing and offering courses. The answers were given using the mysurvio.com internet platform. training of adults. The necessary basis for every lifelong training is the ability and competence of "learning to learn".

The courses are dispersed across Europe, since proposing and offering institutions are located, for example in Germany, Slovakia, Lithuania, Finland and Spain. The institutions planned, structured and prepared various courses in anticipation of future trends in the transport industry, striving to meet the requirements of changing and emerging job profiles. Due to the preparation of various courses, the selected and preferred tools, instruments and studied methods were mentioned in the answers. Sometimes the answers were influenced by the organisers who opted for the use of strict frames and tools, or by the surroundings and prerequisites. The lecturers often offered answers from their lectures, selected their preferred methods and even conclusions from other former courses or participants' wishes in feedback forms were included in the solutions and methodological and structural frames or course boundary conditions. Finally, the answers were collected, structured and are presented below as assessment results.

\subsection{Methods Used in the Lifelong Learning and Training for Adults}

Methods used in lifelong learning courses offered by institutions, limited to the Skilful Project, vary from knowledgebased methods and learning to learn, to evaluation, feedback and knowledge consolidation. Course descriptions contain concrete methods, provide information on the general way in which adult participants are taught in the specific training course and main approaches used in the lectures. The individualisation and adaptation of training content to participants' needs and requirements, issues raised during training, as well as to the level of their understanding, depending on the background of the participants, is important. The different solutions used in the training courses were analysed using the objects of lifelong training methods, ideas for motivation, practical parts and communication. The results of this analysis are summarized and presented in the section below.

Adults, being experienced workers and employees from every branch, do not need academic theories -rendered unnecessary by their experience and real understanding of the job requirements, Instead, they need lectures which combine new theories, help them refresh the knowledge they need, using practical and real experienced-based learning elements.

For this reason, different type of learning approaches would be the best solution in daily life and lifelong training. Smart education enables smart learners to meet the needs and successfully cope with the technologies used at the workplace and necessary for life in the 21 st century.

Asked which types of "traditional" lecture parts were included in the courses, the offering institutions replied: knowledge transfer by frontal teaching in seminar form, 
introduction (including technical introduction of the training systems and reasoning behind the course, explanation of current learning methods and the experiences of other trainees with the training), individual lecturing and traditional individual preparation of open questions. "Traditional" supporting learning methods were indicated as lectures supported by a presentation programme tool with slides, but including lots of pictures or lectures supported by short video clips. The use of visual aids, handling simulations and games are also frequently mentioned as good tools. Case studies, where applicable, are another good method, as is scenario/story-based learning. In all the offered courses, the institutions thought it very important to use different methods during the day and even in the course of a single lesson or unit.

Communication-supported learning is one of the top learning tools for adults or experienced professionals. The lecturer can initiate topic discussions or ask questions. Discussions in the form of a roundtable, spontaneously proceeding discussions or personal experience reports are welcome instruments. The lecturer can introduce these developments in the classroom by encouraging the participants to speak up if there is something they do not understand, ask additional questions or by asking for feedback.

Both participants and lecturers often prefer teamsupported learning, such as collaborative/team-based learning or work in small groups.

Concrete varied, promising and adult suitable methods for application in traditional lectures, combining several elements and for different stages of the teaching and learning process are for example:

$\begin{array}{ll}\text { - } & \text { Science Fiction } \\ \text { - } & \text { TABU } \\ \text { - } & \text { Spectator } \\ \text { - } & \text { Learning slogan } \\ \text { - } & \text { Minutes paper } \\ \text { - } & \text { Active structure } \\ \text { - } & \text { Generating questions for examination/assessment } \\ \text { - } & \text { Brainwriting. }\end{array}$

The more technical a topic is, the more experienced, older, mixed or low-skilled the participants; since practice-supported learning is a very good alternative to traditional lecturer-led presentations, lectures should be enriched with practical experience like on-the-job training, experiential learning, learning by doing or simulation tools like virtual training for practical operations and new technologies, as well as practical exercises suitable for individual, pair and group work. The repetition of practical elements is a factor which guarantees the successful understanding and integration of the related content into the participants' practices and memory.

\subsection{Motivation for and in Lifelong Training Courses}

Motivation can be improved by several methods. The ideas used in lifelong training courses include motivation by establishing suitable organisational framework, using communication, self-motivating and general motivating methods.

The organisational framework is in itself an opportunity to create new and strengthen pre-existent motivation. Some common rules apply: the lecturers have to be respectful to participants. The timetable or working plan should provide for the changes of lecturers and trainers during the day, and set aside sufficient time for discussion, reflection and exchange of experience. Organisers and lecturers should take into account the autonomy and personal responsibility of adult students. Knowing participants' backgrounds and utilising that knowledge in discussions can be a very strong instrument for opening up their minds and creating a positive learning atmosphere. As expected, boring topics should be taught taking into account their tediousness. An opportunity not to lose the participants' attention is the maxim "Legal aspects, yes - but free from time limits". In spite of participants being adults, a reward for well completed tasks or precise work, e.g. sweets, is always a successful tool.

The essential development of new skills, promotion at the workplace and the advantages of staying abreast of the current trends in decision-making are also promising. All participants should know why they learn, for whom and which advantages they may expect for themselves.

Emphasis on the opportunity to learn new technologies and features without reality or time limits, without stress and expectations, automatically results in the creation of positive, open-minded atmosphere. Lectures for older or unexperienced participants should take the form of a safe room, where mistakes are allowed and accepted, even desirable. In case of e-learning, computer- or web-based tools, the advantage of being able to study anytime and anywhere in the world, travel cost savings and no travel time should be proactively communicated.

The use of a clock, allowing the participants to see when the breaks are, and giving them an opportunity to interrupt the lecture whenever necessary, taking into account and meeting their need for short, flexible breaks which increase concentration, are other structural characteristics of adult learning. Organisers and lecturers should schedule short active breaks when using passive teaching methods and vice versa. The practical part should be scheduled after the lunch break, due to the decreased attention and concentration. One of the best advices is: laughter is very welcome!

Self-motivating ideas for adult courses are the introduction of course objects directly relevant for the participants' workplaces 
and discussion. Participants find it motivating to know that the opinion of every last one of them is valuable; this inner feeling contributes to the courses' success. Additionally, courses may allow participants to leave early if required by their activities. Success stories of people who upgraded their qualifications are a welcome motivational factor to be used in different stages of the course. Another motivating factor is the understanding that the improvement of skills makes participants more independent and responsible for specific levels of operative decision-making.

Understanding how new ideas and business changes were developed, the knowledge of the decision-making processes, opening the participants to new ideas, improvements based on the use of artificial intelligence and the manner of their introduction by responsible company managers can contribute to sustainable implementation.

General motivating methods are, e.g. learning mainly based on practical methods, case studies, making course objects relevant for participants, including as many practical examples as possible, no theory without practical implementation/example. Other motivating aspects are: guessing when objects will be introduced using an estimation task, the anticipated results at the end of the lesson, the timing of the teaching and explanation of individual objects, using different types of teaching and training and at least three different methods in the course of the lecture. Games or guesses can be perceived as welcome breaks in trainer-led lectures. The combination of theory and emotions, e.g. storytelling or the use of different sorts of materials, references, infographics, short videos, lectures, podcasts and other resources, can make lessons more interesting. Institutions also offer new online methods of learning and gaining competencies, as well as virtual learning platforms, to engage more people. The use of current IT-oriented decision support tools is a good practical opportunity for updating one's technical skills. High level of interaction during e-learning, achieved by making available different discussion forum threads or a chat tool for interaction among trainees and trainer and discussion about course contents, can be motivating. The use of new technologies (tablets and apps) is a guarantee of greater involvement.

\subsection{Practical Parts of Lifelong Training Courses}

Alternating methods containing interchanging active and passive parts, shifting between interaction in groups, in pairs or individual work, complete each lecture with the practical postulates of lifelong training and future-oriented courses. Support by trainers includes introduction at the beginning of the course and individual prepping where required. Communication tools such as table top exercises and mini-workshop, are some of the popular practical course parts. Excursions can be used to this end, e.g. visits to transport companies, logistics terminals and manufacturers. The organisation of course activities in special educational centres and teaching in other locations, as well as the use of laptops or mobile devices represent a valuable diversifications of classroom-centred schedules.

Several practical exercises should be incorporated, including observation and discovery, not only observing, but handling actual equipment or using the practical parts of the course for medical care and first aid training by incorporating real exercises involving the treatment of typical injuries into occupational health training, practical training for several circumstance in the fire hall, on-the-job training, e.g. in the port; training should consists of introduction, sample, training and test from all its part. The use of laboratories as practical parts is also valid, and may include the conduct of actual experiments at real labs (chemical, ...) or the use of labs equipped specifically for the training of transport experts and workers. Simulation or virtual training are likewise often used as practical lesson parts, involving simulation tools or training by (driving) simulators, virtual learning of technical details in the framework of the learning-by-doing methodology may include 3D models of transport modes and tools.

\subsection{Communication}

With respect to communication, organisers and lecturers are invited to begin with various "Openers" - starting the day with a short self-introduction of participants, with topic-pertinent information or completely random, unexpected facts, because they will be spending the entire day together. One popular opener is completing the sentence "I'm here today although / because ... " or the expectations of the course worded as a weather forecast. Bringing up own issues and ideas related to the lecture increases motivation and subjective involvement.

Adults are valuable participants; asking them for feedback and having them introduce themselves at the beginning of the course can be used as a tool for demonstrating respect. Another communication method at the end of the lecture is a joint short evaluation involving all participants, feedback with hints for improvement, as well as praise for a work well done.

Communication is a very important constituent of the lifelong training because the employees already have experience in their working fields, and their knowledge and experience are very useful. Courses must include parts in which participants can exchange experiences. The teachers must provide motivation and create opportunities for communication, e.g. by using provocative questions, guesses, asking for opinion or experiences. Communication, as group conversation, must be included in every lesson, minimum 10-15 minutes.

The general communication framework implies necessary interaction with the participants. The lecturers and trainers have 
to be motivated to integrate communication into their lessons. Examples of communication events are, for example, introducing the participants and talking about their professions and job experience ("welcome opener"), frontal teaching in seminar form, analysis and the presentation of case studies by participants, opportunity to ask questions and express concerns during lectures or even prepared questions/discussion topics for each topic area. Lunch breaks should also be used as an opportunity for topical discussion, background variability may later be included into discussions, trainees should be given an opportunity to converse with the trainer individually, mini workshops may be organised after each subtopic to encourage comprehensive discussion on the topics just learned, to exchange understanding and experiences. There should be a question \& answer session, as well as the final workshop organised at the end, where experts can share their experience.

Evaluation and feedback are also common communication events. At the end of the day or course, the participants get the "last" word, where they say what they have learned during the course or give feedback to the trainer and closing remarks at the end of the day or several times. A prepared questionnaire as feedback for the course can be a useful support for the communication part.

New learning methods and communication include, for example, personal contact when using e-learning platform, to share materials, download examples and interesting links to alternative educational sources, supplemented by the possibility of scheduling individual meetings with the lecturer to discuss his/her progress in the course. A discussion forum, as the main communication tool, or a chat, as complementary tool, facilitating more informal conversation, are also communication.

\section{CONCLUSIONS}

The lifelong training aspects of future-oriented courses in the framework of the Skilful project cover various transport modes and future trends. (Bekiaris \& Loukea, 2017; Ahern et al., 2019; Infante et al., 2019) In the light of future trends and bearing obstacles in mind, the partners of the Skilful project devised novel training schemes for low to medium skilled transport professionals, with the aim of meeting the requirements of future transport systems and the needs of adult transport professionals by providing lifelong training schemes enhancing quality and transparency, and promoting the recognition of competencies and qualifications to increase the mobility of learners and employees.

Lifelong training courses, not limited to the maritime or transport topic, will therefore include future-oriented contents, a good and practicable registration procedure providing all the necessary information for participants, organisers and lecturers.
Qualified lecturers and trainers capable of tailoring course contents to the specific focus of the course and participants' requirements, giving excellent lectures with motivating parts, summarizing relevant learning material and offering real usable factors, delivering clearly structured lectures including introduction, main content, feedback or even assessment. Practical parts support the learning process for individuals and groups, and strengthen motivation which should be further improved by including remarks of concrete relevance for individual participants, their profession, area of work or even concrete workplace in every lecture. Both lecturers and participants recommend reserved communication parts for different reasons: lecturers for informal learning and as part of the lectures used to evaluate knowledge or strengthen motivation. Another important fact is reserved communication, planned and stimulated by lecturers, the chance for important social contacts which improve soft skills and can likewise be used to exchange experiences and learn from other participants. Participants mostly appreciate the possibility to exchange experiences and compare their own professional frameworks with those of other participants. There should be awareness and recognition of intercultural aspects due to globalisation and at best incorporation of suitable subjects. Lecturers should be able to meet the needs and requirements of mixed groups, e.g. participants from different age groups, with varying level of work experience, understanding and responsibility. A repetition or a new learning to learn method should always be included in the course. Lecturers should furthermore be able to use different, adult-suitable methods and alternate methods in the course of a unit. Focus on emotions to increase the motivation to learn and using various motivating methods will guarantee an interested auditorium for the lecturer.

Every single course should include the lifelong training aspects of the European Union like: communication in mother tongue, communication in foreign languages, mathematical competence and basic competence in science and technology, digital competence, learning to learn, social and civic competences, sense of initiative and entrepreneurship; and cultural awareness and expression.

\section{ACKNOWLEDGEMENT}

J. Edler and V. Infante thank the European Union for the grant of the EU-Skilful project. (H2020 Research and Innovation action Topic: MG-8.3-2016 Assessing future requirements for skills and jobs across transport modes and systems Grant Agreement number: 723989 Start date: 01 October 2016 Duration: 36 months. Skills and competences development of future transportation professionals at all levels SKILFUL.) 


\section{REFERENCES}

A work programme concerning maritime autonomous surface ships - a proposal for a regulatory exercise (MSC 98/20/2).

AAWA, 2016. Remote and autonomous ships: the next steps. Rolls-Royce, London. Available at: http://www.rolls-royce.com/ /media/Files/R/Rolls-Royce/documents/ customers/marine/ship-intel/aawa-whitepaper-210616.pdf, last accessed on: February $10^{\text {th }} 2019$.

Acciaro, M. \& Wilmsmeier, G., 2015. Energy efficiency in maritime logistics chains. Research in Transportation Business \& Management, 17, pp.1-7. Available at: http://dx.doi.org/10.1016/j.rtbm.2015.11.002

Adult Participation in Lifelong Learning 2011 and 2016, Labour Force Survey Available at: http://ec.europa.eu/eurostat/statistics-explained/images/3/39/ Lifelong_learning\%2C_2011_and_2016_\%28\%C2\%B9\%29_\%28\%25_of_the population_aged_25_to_64_participating_in_education_and_training\%29_YB17. png, accessed on February $10^{\text {th }} 2019$.

AEB White Papers, "Six Theories about how 3D printing will change logistics", 2016 (online) available at https://www.aeb.com/intl/media/white-paper-3d-printing.php (assessed 10 February 2019.

AES 2011, Available at: http://eacea.ec.europa.eu/education/eurydice/documents/ thematic_reports/179EN.pdf, accessed on: February $10^{\text {th }} 2019$.

Ahern, A. et al., 2019. Deliverable D2.1 - Best practice on current and emerging training schemes, methodologies and tools in the transport sector and mapping to future training requirements and scenarios. Available at: https://www.Skilfulproject. eu, accessed on: February $10^{\text {th }} 2019$.

Argyros, D., Smith, T., 2013. Lloyds Register, Global marine Trends 2030. Available on: http://www.Ir.org/en/projects/global-marine-trends-2030.aspx, accessed on February $10^{\text {th }} 2019$

Ascencio, L.M. et al., 2014. A Collaborative Supply Chain Management System for a Maritime Port Logistics Chain. Journal of Applied Research and Technology, 12(3), pp.444 - 458. Available at: http://dx.doi.org/10.1016/s1665-6423(14)71625-6.

Bekiaris, A., Loukea, M., 2017. Deliverable D1.1 Future scenarios on skills and competences required by the Transport sector in the short, mid and long-term. Available at: http://Skilfulproject.eu/library?id=78, accessed on: February $10^{\text {th }} 2019$.

Bilger, F., Behringer, F., Kuper, H., 2013. Einführung, in: Bilger, F. u.a. Weiterbildungsverhalten in Deutschland. Resultate des Adult Education Survey 2012. Bielefeld, pp. 13-23.

Blanke, M., Henriques, M., Bang, J., 2017. A pre-analysis on autonomous ships. Available at: https://www.dma.dk/Documents/Publikationer/Autonome\%20skibe_ DTU_rapport_UK.pdf, accessed on: February $10^{\text {th }} 2019$

Castonguay, J., 2015. International Shipping: Globalization in Crisis. Available at: http://www.visionproject.org/images/img_magazine/pdfs/international_shipping. pdf, accessed: February $10^{\text {th }} 2019$.

Cavotec SA, Automated Mooring Systems, 2017. Available at: http://www.cavotec. com/en/your-applications/ports-maritime/automated-mooring, accessed on: February $10^{\text {th }} 2019$.

Council, E. U., 2015. EACEA. Eurydice. Structural Indicators for Monitoring Education and Training Systems in Europe - 2015. Eurydice Background Report to the Education and Training Monitor 2015. Luxembourg. Available at: http://eacea. ec.europa.eu/education/eurydice/documents/thematic_reports/190EN.pdf
Deliverable D1.1 - Future scenarios on skills and competences required by the Transport sector in the short, mid and long-term. Available at: https://www. skilfulproject.eu/library.

DHL Trend Research, 2016. 3D Printing and the future of supply chains. Available at: http://www.dhl.com/content/dam/downloads/g0/about_us/logistics_insights/ dhl_trendreport_3dprinting.pdf, accessed on: February $14^{\text {th }} 2019$

DNV GL Shipping, 2019. Digitalization of Shipping. Available at: https://to2025. dnvgl.com/shipping/digitalization/, accessed on February $10^{\text {th }} 2019$.

DNV GL, 2019. The ReVolt. A new inspirational ship concept. Available at: https:// www.dnvgl.com/technology-innovation/revolt/index.html, accessed on: February $10^{\text {th }} 2019$.

EU Transport Policy, 2014. European Union. Available at: https://europa.eu/ european-union/topics/transport_en.

European Commission, 2014. EU Transport in Figures: Statistical Pocketbook. Publications Office of the European Union. Available at: http://ec.europa. eu/transport/sites/transport/files/facts-fundings/statistics/doc/2014/ pocketbook2014.pdf

Grolinger, K. et al., 2016. Energy Forecasting for Event Venues: Big Data and Prediction Accuracy. Energy and Buildings, 112, pp.222-233. Available at: http://dx.doi.org/10.1016/j.enbuild.2015.12.010.

Hagen, J.E., 2017. Implementing e-Navigation. Boston, p. 159, 165, 175, 183

Hiranandani, V., 2014. Sustainable development in seaports: a multi-case study. WMU Journal of Maritime Affairs, 13(1), pp.127-172. Available at: http://dx.doi.org/10.1007/s13437-013-0040-y.

Infante, V. et al., 2019. Deliverable D3.1 - Proposed future training curricula and courses for the Transport sector, Available at: https://www.Skilfulproject.eu, accessed on: February $10^{\text {th }} 2019$.

Jahn, C., 2017. Digitalization of Seaports-Visions of the Future. p. 1.

Lee, P.T.-W. \& Lam, J.S.L., 2016. Developing the Fifth Generation Ports Model. Dynamic Shipping and Port Development in the Globalized Economy, pp.186-210. Available at:

http://dx.doi.org/10.1057/9781137514295 8 .

Müller, A., Karevska, S., 2016. EY: How will 3D printing make your company link in the value chain? EY's Global 3D printing Report 2016. Available at: http://www.ey.com/ Publication/vwLUAssets/ey-global-3d-printing-report-2016-full-report/\$FILE/eyglobal-3d-printing-report-2016-full-report.pdf, accessed on: February $13^{\text {th }} 2019$.

Parasuraman, R., Sheridan, T.B. \& Wickens, C.D., 2000. A model for types and levels of human interaction with automation. IEEE Transactions on Systems, Man, and Cybernetics - Part A: Systems and Humans, 30(3), pp.286-297. Available at: http://dx.doi.org/10.1109/3468.844354.

Saxon, S., Stone, M., 2017. Container shipping: The Next 50 Years. Available at: https://www.mckinsey.com/industries/travel-transport-and-logistics/our-insights/ how-container-shipping-could-reinvent-itself-for-the-digital-age, accessed on: February $10^{\text {th }} 2019$

Shaikh, S.A., 2017. Future of the Sea: Cyber Security. Available at: https://www.gov. uk/government/uploads/system/uploads/attachment_data/file/663895/Futrure_ of_the_Sea_-_Cyber_Security_Final.pdf, accessed on: February $10^{\text {th }} 2019$.

Statistical Office of the European Communities, 2011. EUROSTAT: Employment of Transport Industry. Available at: http://ec.europa.eu/eurostat. 
Tipping, A., Schmal, A., Duiven, F., 2016. Strategy \& Industry perspectives - 2016 Commercial Transportation Trends. Available at: https://www.strategyand.pwc. com/media/file/2016-Commercial-Transportation-Trends.pdf, accessed on February $10^{\text {th }} 2019$.

Transport in Europe: Key Facts and Trends, 2016. European Environment Agency. Available at: http://www.eea.europa.eu/signals/signals-2016/articles/transport-ineurope-key-facts-trends.

Twomey, B., Berry, T., 2016. Lloyd's register: Ship right procedure - autonomous ships.

UNCTAD Review of maritime transport, 2017. Projected seaborne trade developments 2017-2030. pp. 1-20, 35-42, 78-82, 85-88, table p. 106, 2017, Available on: http://unctad.org/en/PublicationsLibrary/rmt2017_en.pdf, accessed on: February $10^{\text {th }} 2019$

v. Marwyk, K., Treppte, S., 2016. Logistics Study on Digital Business Models: Results. Roland Berger. Available at: https://www.rolandberger.com/de/Publications/ pub_2016_logistics_study_on_digital_business_models_switzerland.html, accessed on: February $10^{\text {th }} 2019$

Vemuri, V.R., 1993. Computer science and engineering curricula. IEEE Transactions on Education, 36(1), pp.108-110. Available at:

http://dx.doi.org/10.1109/13.204826. 